\title{
Poster Exhibit 5: Reconstruction
}

Cite as: Can Urol Assoc J 2021;15(6S2):S130-9. http://dx.doi.org/10.5489/cuaj.7404

\section{UP-101}

Vesicovaginal fistula prevalence, repair patterns, and failures: A retrospective, population-based analysis

Sarah Neu H., $^{1,}$ Bo Zhang', Jennifer A. Locke ${ }^{1,2}$, Refik Saskin³, Sender Herschorn ${ }^{1,2}$

${ }^{1}$ Urology, University of Toronto, Toronto, ON, Canada; ${ }^{2}$ Urology, Sunnybrook Health Sciences Centre, Toronto, ON, Canada; ${ }^{3}$ ICES, Toronto, ON, Canada Introduction: In North America, vesicovaginal fistula (VVF) are most commonly due to iatrogenic injury and have a significant negative impact on quality of life. Failed surgical repair of VVF can lead to ongoing morbidity. The objective of our study is to determine the change in rate of VVF repair and failures over time, and to determine risk factors for surgical repair failure.

Methods: We completed a population-based, retrospective cohort study including all women in Ontario, Canada, aged 18 and older from 20052018. Patients who underwent VVF repair were identified using linked administrative databases and compared to those who required a second VVF repair for primary repair failure. Broken line regression was used to determine changes in the rate of VVF repair over time. Multivariable cox proportional hazard analysis was used to identify risk factors for VVF repair failure.

Results: A total of 814 patients were identified as having undergone VVF repair. Of these patients, 117 required a second surgical repair (14\%). Mean age at time of surgery was 52 years (standard deviation [SD] 15). Most patients had undergone prior gynecological surgery $(68 \%)$, and $76 \%$ were due to iatrogenic injury. Most repairs were performed by urologists $(60 \%)$ and completed transvaginally $(66 \%)$. Annual rate of VVF repair significantly decreased by 0.14/100 000 women in each year from 2005-2009, and insignificantly decreased from 2010-2018. No significant change in VVF re-repair rates were found. Predictors of VVF re-repair included iatrogenic injury as etiology of VVF (hazard ratio [HR] 2.1, 95\% confidence interval [CI] 1.3-3.9, $\mathrm{p}=0.009)$, and having the primary repair done with cystoscopic fulguration ( $\mathrm{HR} 6.1,95 \% \mathrm{Cl} 3.1-11.1, \mathrm{p}<0.0005$,); protective factor was surgeon number of years in practice $(21+$ years: HR $0.5,95 \% \mathrm{Cl} 0.3-0.9$, $\mathrm{p}=0.02$ ). Surgeons with more than 21 years of experience have half as many patients requiring second VVF repair.
Conclusions: VVF repair rates have decreased over time, however, re-repair rates have remained constant over a 13-year time period. latrogenic injury as the cause of VVF is twice as likely to result in the need for a re-repair compared to other etiologies, and repairs done with cystoscopic fulguration were six times as likely to fail compared to a transvaginal or abdominal approach. Surgeon years in practice may protect against the need for a second VVF surgery.

\section{UP-102}

Y-V plasty reconstruction for the treatment of refractory bladder neck contracture: Clinical and patient-reported outcomes

Samer Shamout ${ }^{1,2}$, Henry Yao ${ }^{1,2}$, Kevin V. Carlson ${ }^{1,2}$, Richard I. Baverstock ${ }^{1,2}$ ${ }^{1}$ Department of Surgery, Division of Urology, University of Calgary, Calgary, $\mathrm{AB}$, Canada; ${ }^{2}$ vesia [Alberta Bladder Centre], University of Calgary, Calgary, $\mathrm{AB}$, Canada

Introduction: Highly recurrent bladder neck contracture (BNC) following transurethral resection of the prostate (TURP) is a rare but troublesome condition. With lack of standardized treatment, bladder neck reconstruction remains one of the most accepted therapeutic options for recurrent BNC. This study evaluates the success rate, functional and patient-reported outcomes (PRO) of open Y-V plasty in treatment of refractory BNC after transurethral surgery of the prostate.

Methods: We present medium-term results of 16 consecutive patients with refractory BNC who underwent open $\mathrm{Y}-\mathrm{V}$ plasty at a tertiary care center from 2017-2020. All patients presented with voiding dysfunction after two or more failed attempts of endoscopic treatments. Perioperative evaluation, operative data, and postoperative outcome were analyzed. Postoperative complications were recorded and classified according to the Clavien classification. Functional and patient-reported outcomes were evaluated using standard uroflowmetry and validated self-reported questionnaires. The questionnaires included validated International Prostate Symptom Score (IPSS), IPSS-quality of life (QoL), Overactive Bladder-Validated 8-question Screener (OAB-V8), and International Index of Erectile Function (IIEF)-5 survey items. Results: Sixteen patients underwent the open Y-V plasty procedure, most of whom developed BNC secondary to TURP $(n=11,73 \%)$. Mean age at surgery age (standard deviation) was 66.7 (5.7) years. Mean followup

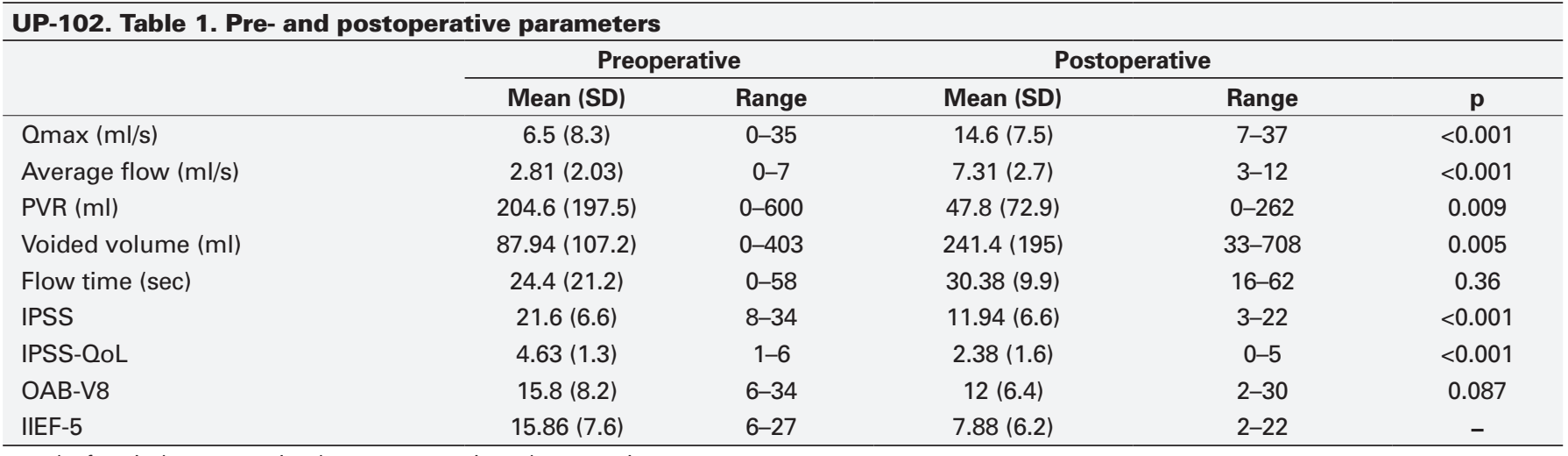

$\mathrm{p}$-value for paired t-test comparison between preoperative and postoperative parameters. 
was 16.1 (6.5) months. Success rate was $100 \%$. Postoperative maximal flow rate (Qmax) improved significantly (preoperative $6.5(8.3) \mathrm{ml} / \mathrm{s}$ vs. postoperative was $14.6(7.5) \mathrm{ml} / \mathrm{s}, \mathrm{p}=0.001)$. Mean post-void residual decreased significantly (preoperative $204.6(197.5) \mathrm{ml}$ vs. postoperative $47.8(72.9) \mathrm{ml}, \mathrm{p}=0.009$ ) (Table 1$)$. De novo urgency was the most common postoperative complication in $47 \%$ of subjects. Age at surgery $(\mathrm{r}=0.52)$ and body mass index $(\mathrm{r}=0.52)$ were positively correlated with changes in OAB-V8 score $(\mathrm{p} \leq 0.05)$.

Conclusions: Y-V plasty represents a safe and viable treatment option with high success rates and favorable patient reported outcomes for refractory bladder neck contracture. Residual storage symptoms are usually attributable to underlying bladder dysfunction, leading to a suboptimal treatment outcome.

\section{UP-103}

Refractory lower urinary tract symptoms (LUTS) following successful urethroplasty: Further examining "LUTS failure"

David W. Chapman', Jordan Bekkema', Keith F. Rourke

${ }^{1}$ Division of Urology, Department of Surgery, University of Alberta, Edmonton, $A B$, Canada

Introduction: An ill-defined proportion of patients undergoing urethroplasty fail to experience improvement in lower urinary tract symptoms (LUTS) despite being stricture-free. We aim to identify the incidence, associations, and causes of "LUTS failure" after urethroplasty.

Methods: Patients undergoing urethroplasty over a six-year period were offered enrollment in a prospective study examining urinary function after urethroplasty. Patients were assessed preoperatively and six months postoperatively using the International Prostate Symptom Score (IPSS). "LUTS failure" was defined as less than three-point improvement. Exclusion criteria were patients with stricture recurrence (inability to pass a $16 \mathrm{Fr}$ cystoscope) or mild preoperative LUTS (IPSS $<7$ ).

Results: Of 365 patients meeting inclusion criteria, mean postoperative IPSS ( 20.3 vs. $5.4, p<0.0001)$ and median urinary quality of life (UQOL) $(5$ vs. $1, \mathrm{p}<0.0001$ ) were significantly improved. Despite being stricture-free, $7.7 \%$ of patients reported "LUTS failure" and $10.1 \%$ reported UQOL nonresponse. On multivariate binary logistic regression, increasing age (odds ratio $[\mathrm{OR}] 1.04,95 \%$ confidence interval $[\mathrm{CI}] 1.01-1.06, \mathrm{p}=0.006)$ and hypospadias (OR 18.2, 95\% Cl 2.1-156.0, $\mathrm{p}=0.008$ ) were associated with "LUTS failure," while stricture location $(p=0.76)$, length $(p=0.14)$, previous urethroplasty $(p=0.96)$, failed endoscopic treatment $(p=0.17)$, type of urethroplasty $(p=0.93)$, and other etiologies were not. Qualitatively, the most common causes of "LUTS failure" were detrusor underactivity $(39.3 \%)$, detrusor overactivity $(21.4 \%)$, pelvic floor dysfunction $(21.4 \%)$, or benign prostatic hyperplasia $(14.3 \%)$. Only increasing age was associated with UQOL non-response (OR 1.03, 95\% Cl 1.01-1.07, $\mathrm{p}=0.02$ ).

Conclusions: While many patients experience improved voiding function after urethroplasty, $7.7 \%$ experience "LUTS failure" and 10.1\% report UQOL non-response. Both occurrences are independently associated with increasing patient age and most commonly related to detrusor underactivity.

\section{UP-104}

Post-void dribbling after urethroplasty: Incidence and associations Lordan Bekkema ${ }^{1}$, Keith F. Rourke

${ }^{1}$ Division of Urology, Department of Surgery, University of Alberta, Edmonton, AB, Canada

Introduction: Post-void dribbling (PVD) is a potential consequence of urethroplasty. Our objective is to examine the impact of urethroplasty on PVD and factors associated with de novo PVD.

Methods: From 2011-2018, patients were enrolled in a prospective, single-center study. PVD was assessed using a five-point scale in response to, "After urinating, do you have post-urination dribbling or leakage of urine?" preoperatively and six months postoperatively. Answers included "Never" (1), "Occasionally" (2), "Sometimes" (3), "Most of the time" (4), or "All of the time" (5). Significant PVD was considered a response of 3-5. Wilcoxon signed-rank test was used to compare pre- and postoperative incidence of PVD. Multivariate binary logistic regression was used to determine the association between new-onset PVD and clinical factors.
Results: A total of 384 patients completed the study. Preoperatively, $46.9 \%$ (180) of patients reported PVD vs. $39.8 \%$ (153) postoperatively ( $\mathrm{p}=0.01$ ). Compared to preoperative status, $25.0 \%$ (96) of patients reported improvement in PVD and $57.0 \%$ (219) reported no change but $18.0 \%$ (67) experienced de novo PVD. On multivariate binary logistic regression, urethroplasty technique was associated with de novo PVD $(p=0.05)$. Patients undergoing anastomotic urethroplasty were less likely to report de novo PVD (odds ratio [OR] 0.33, 95\% confidence interval [Cl] 0.13-0.83, $\mathrm{p}=0.02$ ) compared to onlay or staged techniques. No other factor was associated with de novo PVD, including age $(p=0.59)$, stricture length $(p=0.71)$, location $(p=0.50)$, etiology $(p=0.59)$, failed endoscopic treatment $(p=0.18)$, previous urethroplasty $(p=0.55)$, or stricture recurrence $(p=0.78)$. De novo PVD was not associated with patient dissatisfaction $(10.1 \%$ vs. $7.6 \%, p=0.49)$.

Conclusions: PVD is common in patients with urethral stricture and there is an overall improvement after urethroplasty but $18.0 \%$ of patients will experience de novo PVD. Patients undergoing anastomotic urethroplasty are less likely to experience de novo PVD.

\section{UP-105}

24 months' followup of dorsal buccal mucosal graft urethroplasty for vesicourethral anastomotic stricture postradical prostatectomy

Walid Shahrour ${ }^{1}$, Waleed Shabana ${ }^{1}$, Ahmed Kotb ${ }^{1}$, Owen Prowse', Thomas Tablowski', Hazem Elmansy

${ }^{1}$ Urology Department, Northen Ontario School of Medicine, Thunder Bay, ON, Canada

Introduction: We sought to assess urinary functional and erectile outcomes after two years post-dorsal buccal mucosal graft (BMG) for the repair of refractory vesicourethral anastomotic stricture/stenosis (VUAS) post-open radical prostatectomy.

Methods: We retrospectively reviewed collected data of patients who underwent BMG urethroplasty following at least three interventions after urethrovesical anastomotic stricture/stenosis post-radical prostatectomy. Patients were included if they completed 24 months after surgery. Patient demographics, preoperative continence status, number of dilations, and urine flow preoperatively and postoperatively were collected. Trial of void and retrograde urethrogram were done after three weeks. Patients were followed at three, nine, 15 , and 24 months by flow rate, post-void residual urine volume, cystourethroscopy, and institutional standardized non-validated questionnaires.

Results: All patients had received adjuvant radiotherapy. Strictures were in the anastomotic site and median stricture length was $2.5 \mathrm{~cm} \mathrm{(2-3).} \mathrm{All}$ patients were incontinent preoperatively, with mean preoperative flow of $5 \mathrm{~mL} / \mathrm{s}(3-7 \mathrm{~mL} / \mathrm{s})$. Mean operative time and blood loss were 177 minutes and $250 \mathrm{~mL}$, respectively. We did not record any case of intraoperative rectal injuries. Erectile function remained mostly unchanged compared to preoperative status. Median postoperative urine flow at three, six, 12, and 24 months was $20,22,25$, and $26 \mathrm{~mL} / \mathrm{s}$, respectively. Success rate was $100 \%$ at 24 months. Forty percent of patients reported very satisfied with surgery. One patient had AUS subsequently.

Conclusions: Long-term followup of dorsal BMG urethroplasty post-vesicourethral anastomotic stricture/stenosis has a promising urinary functional outcome Dorsally placed BMG eliminate risk of rectal injuries associated with other approaches.

\section{UP-106}

Patient-perceived changes in penile appearance post-urethroplasty Dylan Hoare', Jordan Bekkema ${ }^{1}$, Keith F. Rourke

'Division of Urology, Department of Surgery, University of Alberta, Edmonton, AB, Canada

Introduction: Alterations in penile curvature or length post-urethroplasty are associated with patient dissatisfaction but are poorly described. This study aims to define the incidence and associations of patient-reported penile curvature and shortening after urethroplasty.

Methods: From 2011-2018, 387 patients completed enrollment in a prospective, single-center study assessing patient-reported outcomes preoperatively and six-months post-urethroplasty. Primary outcomes of perceived penile shortening and curvature were assessed at six months followup. 
Descriptive statistics were used to summarize findings, while univariate and multivariate binary logistic regression was used to identify associations between loss of penile length or chordee with other clinical factors. Results: Of the 387 patients, mean age was 49.5 years with mean stricture length of $4.5 \mathrm{~cm}$. Postoperatively, $12.7 \%$ of patients perceived penile curvature $(8.0 \%$ "somewhat", $4.7 \%$ "severe") and $22.8 \%$ of patients perceived penile shortening (14.5\% "somewhat", $8.3 \%$ "a lot"). Multivariate binary logistic regression identified stricture location $(p=0.02)$ to be associated with perceived curvature, while prior urethroplasty $(p=0.17)$, type of urethroplasty ( $\mathrm{p}=0.08$ ), and other factors were not. Specifically, penile (odds ratio [OR] 4.27, 95\% confidence interval [Cl] 1.56-11.68, $\mathrm{p}=0.005$ ) and panurethral (OR 10.15, 95\% Cl 3.46-29.77, $\mathrm{p}<0.001)$ locations were independently associated with this outcome. In a multivariate model, panurethral strictures (OR 4.23, 95\% Cl 1.10-16.20, $\mathrm{p}=0.04$ ) and hypospadias (OR $5.46,95 \% \mathrm{Cl} 1.32-22.70, \mathrm{p}=0.02)$ were associated with patient perceived shortening, while other factors, such as age $(p=0.19)$, type of urethroplasty $(\mathrm{p}=0.14)$, and other stricture etiologies or locations were not.

Conclusions: Clinically significant changes in penile appearance are more common post-urethroplasty than initially thought. Stricture location and etiology are important predictors of these patient-perceived changes.

\section{UP-107}

The incidence and associations of 90-day complications after urethroplasty

Ryan Noble ${ }^{1}$, Keith F. Rourke', Nathan Hoy

${ }^{1}$ Department of Surgery, University of Alberta, Edmonton, AB, Canada Introduction: Our objective is to determine the incidence of 90-day complications after urethroplasty, as well as associated predisposing factors. Methods: A retrospective review was performed on patients undergoing urethroplasty for urethral stricture at the University of Alberta from August 2003 to June 2020. Abstracted variables included the incidence/number/ type of complications, Clavien-Dindo grade (CDG), and patient comorbidities based on the corresponding component of the Charlson comorbidity index $(\mathrm{CCl})$ among others. The primary outcome was incidence of 90-day complications. A CDG grade $\geq 2$ was defined as significant. Descriptive statistics and regression were used to examine the factors associated with 90-day complications.

Results: Mean age of the 1611 patients in our analysis was 47.6 years (18-94), mean stricture length was $4.5 \mathrm{~cm}, 82.0 \%$ failed prior endoscopic treatment, and $17.6 \%$ had prior urethroplasty. Ninety-day complications $(C D G \geq 2)$ occurred in $7.9 \%$ of patients. These were wound-related $(3.5 \%)$, urinary tract infection $(3.4 \%)$, cardiovascular $(0.4 \%)$, catheter-related $(0.2 \%)$, hematuria $(0.1 \%)$, retention $(0.1 \%)$, or other $(0.2 \%)$. On univariate analysis, stricture location $(p=0.04)$, length $(p=0.009), C C I(p<0.0001)$, prior urethroplasty $(p=0.01)$, and preoperative bacteriuria $(p=0.002)$ were associated with 90 -day complications, while age $(p=0.27)$, etiology $(p=0.15)$, smoking $(p=0.17)$, body mass index $>35(p=0.27)$, failed endoscopic treatment $(p=0.84)$, indwelling suprapubic catheter $(p=0.68)$, and type of urethroplasty $(p=0.09)$ were not. On multivariate analysis, increasing $\mathrm{CCl}$ (odds ratio [OR] 1.32, 95\% confidence interval [Cl] 1.10-1.59, $\mathrm{p}=0.004)$, prior urethroplasty $(\mathrm{OR} 1.85,95 \% \mathrm{Cl} 1.08-3.17, \mathrm{p}=0.02)$ and preoperative bacteriuria (OR $1.69,95 \% \mathrm{Cl} 1.14-2.52, \mathrm{p}=0.01$ ) remained associated with rates of 90-day complications.

Conclusions: Patients with increased comorbidities, prior urethroplasty, and preoperative bacteriuria are at increased risk for complications after urethroplasty and should be counselled accordingly in a shared decisionmaking model of care.

\section{UP-108 \\ Morbidity and predictors for delayed recognition of Iatrogenic ureteric injuries}

Lennifer A. Locke' ${ }^{\prime}$, Sarah Neu', Sender Herschorn'

${ }^{1}$ Surgery, Sunnybrook Health Sciences Centre, University of Toronto, Toronto, ON, Canada

Introduction: Although iatrogenic ureteric injuries (IUI) are rare, intraoperatively unrecognized IUI can have significant consequences. The focus of our study was to characterize the associated morbidity and identify predictors of delayed recognition of IUI.

Methods: Sunnybrook Health Sciences Centre Research Ethics Board approved the study. Patients with a diagnosis of IUI between 2002 and 2020 were identified through an institutional electronic medical record system. Data pertaining to the demographic characteristics, diagnosis and management of IUI, and overall outcomes was collected retrospectively. Results: Of the 103 patients identified, $83 \%$ were female, 52\% had previous abdominal surgery, and $18 \%$ had previous radiation. The median age was 67 (21-88). Twenty percent had delayed recognition of IUI. Although delayed recognition was not a significant predictor for poor outcome after surgery (i.e., hydronephrosis, ureteric stricture/obstruction), it was associated with significant morbidity to the patient (i.e., additional procedures) and increased cost to the healthcare system (i.e., readmission to hospital). Patients who underwent laparoscopic surgery had an 11 times more likely chance of delayed presentation of IUI as compared to patients who underwent open surgery (odds ratio [OR] 11.515, $\mathrm{p}=0.000$ ). Conclusions: Delayed recognition of IUI is associated with significant patient morbidity and cost to the healthcare system. In this retrospective case series, we identified laparoscopic surgery as a predictor for delayed recognition of IUI. This information underscores the need for future studies to optimize intraoperative techniques to identify IUI, particularly in laparoscopic cases

\section{UP-110}

Characterizing clinical differences between idiopathic and traumatic stricture patients: Analysis from a single institution

Alexander Kiciak ${ }^{1}$, Ryan Noble', Nathan Hoy ${ }^{1}$, Keith F. Rourke

${ }^{1}$ Division of Urology, University of Alberta, Edmonton, AB, Canada

Introduction: Male urethral strictures (especially bulbar) are most commonly idiopathic. It is assumed that these strictures are related to trauma. However, many patients with idiopathic urethral strictures do not recall any specific trauma and there may be other genetic, systemic, or immunological factors involved. Our purpose was to compare clinical factors between patients with idiopathic and traumatic urethral strictures.

Methods: A retrospective review of patients undergoing bulbar urethroplasty with either idiopathic or traumatic etiology at the University of Alberta from August 2003 to May 2019. Patients with previous urethroplasty or unrelated etiologies were excluded. Patients with acute urethral trauma were excluded, however, patients with a history of subacute or repetitive perineal trauma were included in the analysis.

Results: A total of 832 patients (mean age $43.6 \pm 15.0$ years) were identified and analyzed; 584 patients $(70.2 \%)$ were diagnosed with an idiopathic etiology. Rates of prior endoscopic treatment (2.4 vs. 2.6, $\mathrm{p}=0.65)$ and age (43.9 vs. 43.0 years, $p=0.41$ ) were similar between the idiopathic and traumatic stricture groups. The idiopathic group, when compared to the traumatic etiology, had strictures which were longer $(3.8 \mathrm{vs} .3 .3 \mathrm{~cm}$, $\mathrm{p}=0.03)$, were less likely to be smokers $(12.5 \%$ vs. $22.6 \%, p<0.001)$, and more likely to be obese (body mass index $[\mathrm{BMI}]>35)(14.0 \%$ vs. $8.1 \%$, $p=0.02)$. There was a significant difference $(p<0.0001)$ in urethoplasty technique between the groups (idiopathic stricture: $70.2 \%$ onlay with buccal mucosa; traumatic structure: $52.0 \%$ anastomotic urethroplasty). Both idiopathic and traumatic stricture groups had similar rates of diabetes $(9.9 \%$ vs. $7.3 \%, p=0.22)$ and chronic obstructive pulmonary disease $(1.7 \%$ vs. $1.6 \%, \mathrm{p}=0.92)$.

Conclusions: There are some key differences between idiopathic and traumatic bulbar urethral strictures. Further investigation of systemic, immunological, metabolic, or wound healing factors may be warranted to elucidate the nature of men with idiopathic urethral strictures. 


\section{UP-111}

\section{The burden of urethral stricture disease in the province of} Ontario

R. Christopher Doiron' ${ }^{1}$, Marlo Whitehead ${ }^{2}$, Christopher M. Booth ${ }^{2,3,4}$, D. Robert Siemens ${ }^{1,3,4}$

${ }^{1}$ Urology, Queen's University, Kingston, ON, Canada; ${ }^{2}$ ICES Queen's, Health Services and Policy Research Institute, Queen's University, Kingston, ON, Canada; ${ }^{3}$ Oncology, Queen's University, Kingston, ON, Canada; ${ }^{4}$ Division of Cancer Care and Epidemiology, Queen's University, Kingston, ON, Canada

Introduction: Urethral stricture disease (USD) is a rare, but frequently morbid condition, while access to Canadian surgeons with expertise in urethroplasty is lacking. We describe the burden of USD in the province of Ontario and explore management patterns.

Methods: All male patients with USD in the province of Ontario who received care related to their diagnosis between April 2002 and March 2020 were identified using data from the Institute for Clinical Evaluative Sciences. Analysis of healthcare utilization included outpatient, inpatient, and emergency department visits for care related to their stricture diagnosis. Results: A total of 118721 men were identified with a urethral stricture diagnosis during the study period: 66868 incident cases and 51853 prevalent cases. Overall median (interquartile range [IQR]) age at time of diagnosis was 61 (44-72). Over the study period, $2.1 \%(n=2448)$ of patients visited emergency departments (ED) $\geq 1$ time due to USD, while $27.3 \%$ ( $n=32390$ ) had $\geq 1$ ED visits for diagnoses other than USD, determined to be a complication secondary to USD. A total of $12.2 \%(n=14$ 464 ) of patients required $\geq 1$ urological USD-associated intervention in the $E D$, while $1.7 \%(n=2102)$ required $\geq 3$. Over half $(52.2 \%, n=61,982)$ of patients were seen in outpatient consultation directly related to USD and $68 \%(n=80,773)$ were seen for a non-USD diagnosis determined to be a complication secondary to USD. Patients underwent a mean (standard deviation $[S D])$ of $7.6( \pm 23.5)$ diagnostic procedures and 1.4 $( \pm 5.4)$ endoscopic interventions as treatment of their USD during the study period. A total of 1386 patients (1.2\%) underwent a single open reconstruction for treatment of their urethral stricture, while $253(0.2 \%)$ had $\geq 2$ open procedures during the study period.

Conclusions: USD is not rare and carries a significant burden on the healthcare system in Ontario, with few receiving definitive treatment with urethroplasty.

\section{UP-112}

Predictors of perioperative and one-year renal functional outcomes in laparoscopic kidney donors

Ryan Sun ${ }^{1}$, Lourens Jacobs², Angie Liu², Thomas McGregor ${ }^{3}$, Rahul K. Bansal'

${ }^{1}$ Section of Urology, University of Manitoba, Winnipeg, MB, Canada; ${ }^{2}$ Max Rady College of Medicine, University of Manitoba, Winnipeg, MB, Canada; ${ }^{3}$ Urology, Queen's University, Kingston, ON, Canada

Introduction: Ensuring the safety of living kidney donors is paramount, especially as donor criteria are expanded to meet the growing demand of kidney transplantation. In this study, we aimed to assess potential predictors of perioperative outcomes in those undergoing laparoscopic donor nephrectomy (LDN).

Methods: This was a retrospective study involving all donors who underwent LDN from 2011-2020 at the Health Sciences Centre in Winnipeg, Canada. Various patient clinical and anatomical factors were compared with operative outcomes, kidney biopsy findings, and post-donation renal function, measured as estimated glomerular filtration rate (eGFR), during the one-year postoperative period.

Results: A total of 197 donors were identified. LDN was well-tolerated regardless of patient clinical and anatomical characteristics. Age $>60$ years correlated with the presence of chronic histopathological changes on biopsy, corresponded to lower pre- and post-donation renal function $(p<0.01)$, and was predictive of eGFR $<45$ at one year $(p<0.01)$. Smoking and hypertension were associated with histopathological changes and statistically non-significant decline in eGFR. Controlling for age, interstitial fibrosis on biopsy remained predictive of eGFR $<45$ at one year.
Conclusions: Among carefully selected kidney donors, LDN appears to be safe, with excellent perioperative risk profile regardless of age, gender, comorbidities, side of nephrectomy, and number of renal vessels. Advancing age is predictive of significantly lower post-donation renal function within one year, likely secondary to baseline histopathological changes in the donor kidney. Donors with known risk factors and adverse biopsy findings should be offered close followup and counselling to minimize further renal deterioration.

\section{UP-113}

Characterizing renal transplant recipients with urethral strictures Lulie Wong', David I. Harriman', Mark K. Nigro', Christopher Y. Nguan' ${ }^{1}$ Department of Urologic Sciences, University of British Columbia, Vancouver, BC, Canada

Introduction: Urethral strictures are a relevant cause of male bladder outlet obstruction. With a history of catheterization and low urine output (UO) pre-transplant, many renal transplant recipients (RTRs) may be at risk of urethral stricture disease post-transplant. Little research has been done regarding the prevalence of urethral strictures in Canadian RTRs. The objective of this study was to characterize urethral stricture disease in RTRs from a high-volume Canadian transplant center.

Methods: This is a single-center, retrospective chart review analyzing the demographics of RTRs who had a urethral stricture pre- or post-kidney transplant. Data was extracted from patient charts and descriptive analyses were conducted.

Results: Of the 1037 patients who underwent renal transplant at our center from October 2009 to October 2019, 23 (2.22\%) were found to have urethral stricture. Analysis of these patients showed median age of 55 years, with $34.8 \%$ living donor transplants. Pre-transplant, $17.4 \%$ were anuric, while $60.8 \%$ had $\cup O$ of $<1 \mathrm{~L} ; 26.1 \%$ experienced delayed graft function, and $17.4 \%$ had acute rejection. Three had known urethral strictures pre-transplant, two had strictures found at time of transplant, while 18 had strictures discovered post-transplant. Almost half (44.4\%) of these patients had recurrent strictures post-transplant. Of the posttransplant stricture patients, $11.1 \%$ had postoperative retention and $5.6 \%$ had postoperative urinary react infection. Median time between transplant and cystoscopy showing stricture was 92 days (range 8-618). Stricture treatment involved 15 dilations, eight urethrotomies, and nine urethroplasties, with seven patients requiring no intervention.

Conclusions: This study is one of the largest to characterize the incidence of urethral strictures in RTRs. It showed a prevalence of $2.22 \%$, compared to a population prevalence of $0.9 \%$. Urethral strictures are an important complication to monitor for in RTRs, and further research should be done to investigate the effect on transplant outcomes.

\section{UP-114}

Does the skin to vessel distance for renal transplant recipients predict surgical outcomes?

Braden Millan', Shahid A. Lambe', Anil Kapoor', Kevin R. Piercey', Yuding Wang ${ }^{1}$, Somin $\mathrm{Nam}^{2}$

'Department of Surgery, Division of Urology, McMaster University, Hamilton, ON, Canada; ${ }^{2}$ Michael G. DeGroote School of Medicine, McMaster University, Hamilton, ON, Canada

Introduction: Body mass index (BMI) and weight circumference do not denote differences in fat distribution or muscle mass. It is unknown whether differences exist between body fat distribution and surgical outcomes in renal transplant recipients. The objective of this study was to identify whether the distance from external iliac vessels to skin correlates with findings in surgical and long-term graft outcomes.

Methods: A retrospective chart review was completed of patients who underwent a renal transplant from 2016-2019 at a single center. The Clavien-Dindo classification system was used to define postoperative complications. Descriptive statistics were analyzed (mean \pm SEM); logistic regression determined predictors of differences between skin to vessel distance and other variables.

Results: Complete data were available for 75 patients undergoing renal transplant from 2017-2019. Fifty percent of patients $(n=38)$ had one 
postoperative complication in the year following renal transplantation Patients with complications had a higher mean vessel to skin distance $(139.6 \pm 4.9 \mathrm{~mm}$ vs. $121.4 \pm 5.2 \mathrm{~mm}, \mathrm{p}=0.0124)$ and body mass index (BMI) $\left(29.0 \pm 0.8 \mathrm{~kg} / \mathrm{m}^{2}\right.$ vs. $\left.26.3 \pm 0.9 \mathrm{~kg} / \mathrm{m}^{2}, \mathrm{p}=0.0322\right)$. There were no significant differences in warm ischemic time, sex, age, or other comorbidities. In the cohort with the greater mean skin to vessel distance, there were higher rates of delayed graft function $(16$ vs. 0 patients, $p<0.0001)$ and longer lengths of stay ( $11.4 \pm 1.7$ days vs. $6.3 \pm 0.2$ days, $p<0.0001)$. Logistic regression for the skin to vessel distance and $\mathrm{BMI}$ revealed an area under the ROC curve of 0.667 and 0.644 , respectively.

Conclusions: These data suggest that a longer skin to external iliac vessel distance, as determined by cross-sectional imaging, is slightly $(p=0.0124)$ more predictive of postoperative complications than BMI. Additionally, longer distances from skin to the external iliac vessels were associated with higher rates of delayed graft function and longer length of hospital stay.

\section{UP-115}

\section{Urethral bulking agents for the treatment of stress urinary} incontinence in women: A systematic review

\section{Venetia Hoe ${ }^{1,2}$, Britt Haller ${ }^{1,2}$, Henry Yao ${ }^{1,2}$, Helen $O^{\prime}$ Connell ${ }^{1,2}$}

${ }^{1}$ Urology, Western Health, Melbourne, Australia; ${ }^{2}$ Surgery, University of Melbourne, Melbourne, Australia

Introduction: Stress urinary incontinence (SUI) is a common and debilitating condition predominantly affecting women. The use of urethral bulking agents (UBAs) is a well-established treatment for SUI. Glutaraldehyde cross-linked bovine collagen (Contigen ${ }^{\circledR}$ ) has now been superseded by new synthetic, non-absorbable bulking agents. Currently marketed UBAs include polyacrylamide hydrogel $\left(\right.$ Bulkamid $\left.^{\circledR}\right)$, polydimethylsiloxane (Macroplastique $^{\circledast}$ ), carbon-coated zirconium oxide (Durasphere ${ }^{\circledR}$ ), calcium hydroxylapatite $\left(\right.$ Coaptite $\left.{ }^{\circledR}\right)$, with the latest product being a polydimethylsiloxane silicone gel that polymerises when injected (Urolastic ${ }^{\circledR}$ ). Despite the common use of UBAs, clinical data comparing its outcomes are limited. The aim of this study was to perform a systematic review to assess and compare the efficacy and safety of all urethral bulking agents available for the treatment of SUI in women.

Methods: This systematic review was conducted in accordance with the PRISMA guideline. A systematic search was conducted using the Ovid Medline, Embase, and PubMed databases. Studies were included if they involved women who underwent either Bulkamid, Macroplastique, Durasphere, Coaptite, or Urolastic injections for the treatment of SUI. A total of 583 articles were screened with 56 articles included. A qualitative analysis was performed.

Results: The newer synthetic urethral bulking agents are not inferior to Contigen, with variable mean success rates of $30-80 \%$ in the short-term $(<24$ months). Better long-term ( $>24$ months) success rates were found with Bulkamid (44\% to $<80 \%)$, Coaptite $(68.5-70 \%)$, and Macroplastique $(21-60 \%)$ on qualitative review. Urinary tract infection rates were similar between bulking agents (1.9-5.6\%), although temporary acute urinary retention was more commonly associated with Coaptite (32.8\%) and de novo urgency in Durasphere (16.9\%). Significant complications, such as migration into lymph nodes, was reported with Durasphere. Erosion was reported with Macroplastique, Coaptite, and Urolastic, with a rate as high as $24.6 \%$ in one study of Urolastic.

Conclusions: There is most data available to support the use of Bulkamid and Macroplastique, which have shown a short-term efficacy of 29.8 $9.7 \%$ and $40-85 \%$, respectively, and long-term efficacy of $42 \%$ to $<80 \%$ and $21-60 \%$, respectively. Bulkamid appears to have a more favorable safety profile, with no cases of erosion or migration of product associated with its use.

\section{UP-116}

Age-stratified continence outcomes of robotic-assisted radical prostatectomy

Iman Sadri', Adel Arezki ${ }^{1}$, Ahmed S. Zakaria Ahmed ${ }^{2}$,Félix Couture ${ }^{3}$ David-Dan Nguyen', Pierre Karakiewicz ${ }^{2}$, Kevin C. Zorn ${ }^{2}$

${ }^{1}$ Faculty of Medicine, McGill University, Montreal, OC, Canada; ${ }^{2}$ Division of Urology, Centre Hospitalier de I'Université de Montréal, Montreal,
QC, Canada; ${ }^{3}$ Division of Urology, Centre Hospitalier Universitaire de Sherbrooke, Sherbrooke, QC, Canada

Introduction: Incontinence after robot-assisted radical prostatectomy (RARP) significantly impacts quality of life. This study aimed to compare the age-stratified continence outcomes in Canadian men undergoing RARP. Methods: A retrospective review was performed on a prospectively maintained database of 1737 patients who underwent RARP for localized prostate cancer between 2007 and 2019. Patients were stratified into five groups based on age - group $1: \leq 54$ years $(n=245)$; group 2: 55-59 years $(n=302)$; group $3: 60-64$ years $(n=386)$; group 4 : $65-69$ years $(n=348)$; and group 5: $\geq 70$ years $(n=116)$. Functional outcomes were assessed up to 36 months. Log-rank and multivariable Cox regression analyses were performed to compare the time to recovery of pad-free continence by age group.

Results: Continence rates of groups $1-5$ were, respectively, $90.2 \%, 79.1 \%$, $80.4 \%, 71.4 \%$, and $59.8 \%$ at one-year followup $(\mathrm{p}<0.001)$. After three years, groups 1 through 5 had continence rates of $97 \%, 91.7 \%, 89.3 \%$, $81.4 \%$, and $77.6 \%$, respectively $(p<0.001)$. Median time to recovery of continence was 58, 135, 140, 152 and 228 days, respectively (Fig. 1). Among men who remained incontinent, older patients consistently required more pads (Fig. 2). In Cox proportional hazard model, groups 2, 3, 4, and 5 were, respectively, $33 \%(p<0.001), 34 \%(p<0.001), 33 \%(p=0.001)$, and $41 \%(p=0.005)$ more likely to remain incontinent compared to group 1.

Conclusions: Age is associated with significantly lower rates of continence recovery, longer time to recovery of continence, and more severe cases of incontinence after RARP.

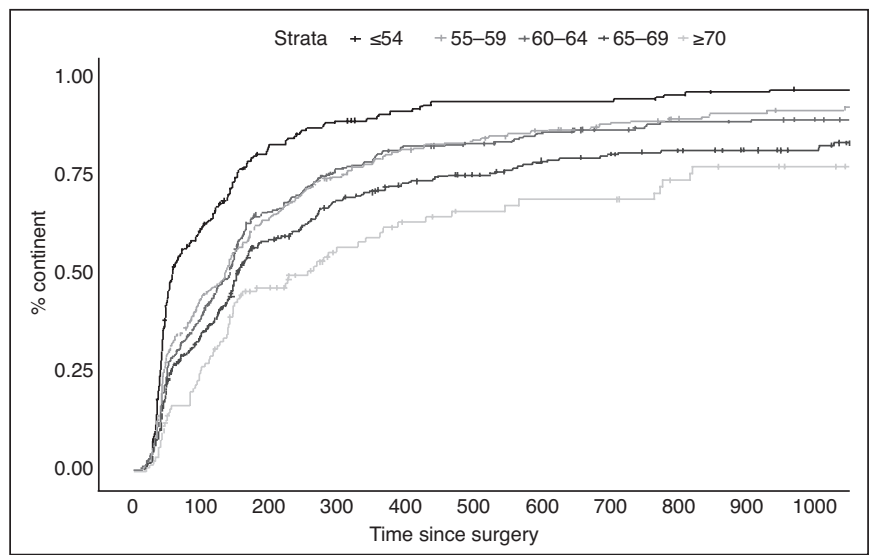

UP-116. Fig. 1. Age-specific continence recovery of all patients after surgery.

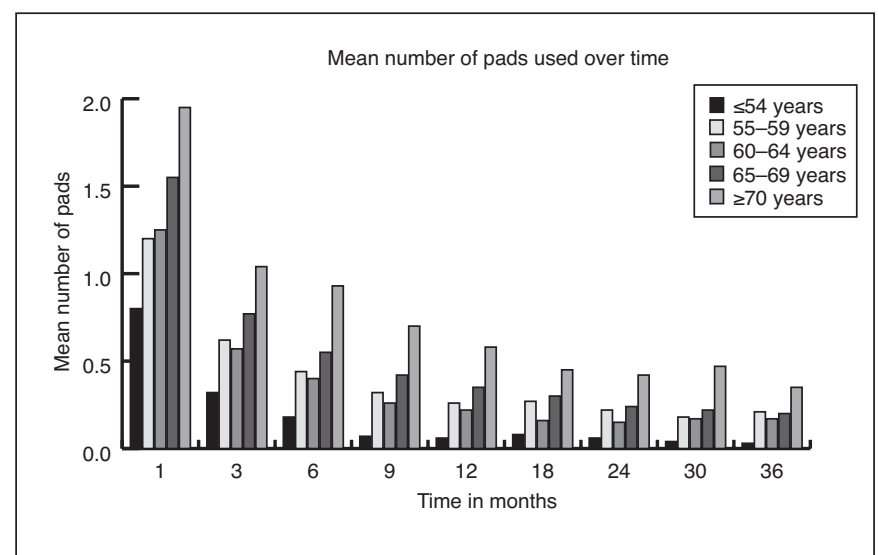

UP-116. Fig. 2. Mean number of pads used over time by incontinent patients in each group. 
UP-117

Long-term outcomes of polyacrylamide hydrogel $\left(\right.$ Bulkamid $^{\circledR}$ ) treatment in women with stress urinary incontinence

Venetia Hoe ${ }^{1,2}$, Henry Yao ${ }^{1,2}$, Karla Gough ${ }^{3}$, Helen $\mathrm{O}^{\prime}$ Connell ${ }^{1,2}$

${ }^{1}$ Urology, Western Health, Melbourne, Australia; ${ }^{2}$ University of Melbourne, Melbourne, Australia; ${ }^{3}$ Peter MacCallum Cancer Centre, Melbourne, Australia

Introduction: Stress urinary incontinence (SUI) is a highly prevalent condition among women, with a significant impact on quality of life. The use of urethral bulking agents is a well-established treatment for SUI. Despite the common use of polyacrylamide hydrogel $\left(\right.$ Bulkamid $\left.^{\circledR}\right)$ since its introduction in 2006, long-term clinical data is limited. The aim of this study was to determine the long-term outcomes and durability of Bulkamid transurethral injections in women with SUI.

Methods: Between January 2012 and December 2019, 171 consecutive female patients underwent transurethral Bulkamid injections for the treatment of SUI by a single surgeon. Women were evaluated with validated questionnaires preoperatively, four-weeks postoperatively, and at final assessment time, ranging from 4-106 months from the initial injection. Results: A total of 171 patients were included; 35 patients were lost to followup. Of the remaining 136 patients, 29 (21\%) had failed Bulkamid treatment and proceeded to alternative anti-incontinence treatment; 107 patients completed the final assessment. The mean age of the responders was 63 (range 25-93). Forty-one patients (38\%) had prior anti-incontinence surgery; 64 patients $(60 \%)$ underwent two injections with a median time of three months between injections. Mean followup time was 50 months (range 4-106) from last injection. Success rates (defined as PGI-I $\geq 2$ ) of $60 \%$ was obtained at followup time of $<1$ year, $48 \%$ at $1-2$ years, $46 \%$ at $3-4$ years, $57 \%$ at $5-6$ years, and $53 \%$ at $7-8$ years. Overall, $89.6 \%$ of women would be willing to refer Bulkamid injections for the treatment of SUI to a friend. Urinary tract infection and acute urinary retention were the most common complications reported, with rates of $4.7 \%$ and $4.7 \%$, respectively.

Conclusions: Overall, $21 \%$ of women failed treatment with Bulkamid injection and proceeded to alternative treatment for SUI. Of the remaining $79 \%$ of patients, a success rate of $53 \%$ was achieved at $7-8$ years of followup. Rates of adverse events were low. Although less efficacious than open surgery, Bulkamid injections offer women the option of less invasive therapy with lower complication rates and a promising chance of success in the long-term. Larger, prospective, comparative studies are warranted.

\section{UP-118}

Treating overactive bladder with transcutaneous tibial nerve stimulation: Does increasing the volume of stimulation sessions improve patient outcomes?

Christopher Ciampa ${ }^{1}$, Anthony J. Kiosoglous ${ }^{1}$

'Urology, Queen Elizabeth II Jubilee Hospital, Brisbane, Australia

Introduction: Transcutaneous tibial nerve stimulation (TTNS) is a lowrisk, non-surgical treatment for overactive bladder (OAB). TTNS indirectly provides neuromodulation to the sacral plexus by passing mild electrical pulses to the tibial nerve, altering bladder activity. Recent systematic review shows TTNS as effective in modulating voiding and storage function of the bladder, with overall improvement in International Prostate Symptom Score (IPSS) parameters in $47-56 \%$ of patients; $70-80 \%$ of pharmaceutically naive patients benefit from a 'standard' TTNS regimen (1x30-minute session/week and review after 12 weeks), but only $30-40 \%$ of medically refractory patients show benefit. The aim of this study was to assess if increasing frequency of TTNS sessions improves patient outcomes and quality of life (QoL).

Methods: Thirty-one patient were included in the study with increasing number of TTNS sessions to assess IPSS and QoL outcomes; 13 were male and 17 female patients all aged 20-75 years (8/31 were pharmaceutically naive). IPSS was assessed pre- and post-TTNS. A transcutaneous electrical nerve stimulation (TENS) machine was used (active electrode placed behind medial malleolus and earth electrode placed over shin of same leg); sessions were conducted 4-7 times/week (average five times/ week) for 30 minutes. Patients were reviewed after six weeks.

\begin{tabular}{lcc}
\hline UP-1 18. Table 1. Pre- and post-TTNS treatment results \\
\hline & Pre-TTNS treatment & $\begin{array}{c}\text { Post-TTNS } \\
\text { treatment }\end{array}$ \\
\hline IPSS range & $\begin{array}{c}17-21 \text { (moderate/ } \\
\text { severe) }\end{array}$ & $8-16$ (moderate) \\
IPSS mean & 19 (moderate) & 11.7 (moderate) \\
QOL range & $5-6$ (unhappy/ & $1-5$ (pleased/ \\
& terrible) & unhappy) \\
QOL mean & 5.5 (unhappy/ & 1.6 (pleased) \\
& terrible) & 13.3 (moderate) \\
Total IPSS (average & 24.5 (severe) & \\
for group) & &
\end{tabular}

Results: Most patients (94\%) showed a marked reduction in IPSS and improvement in QoL score. Mean total IPSS improved by $70.6 \%$ and QoL score improved by $67 \%$. The most notable IPSS improvements were seen in reduction of frequency, urgency, nocturnal frequency, and QoL effects. Six percent had ongoing symptoms post-TTNS requiring further management (insertion of sacral neuromodulator device or referral for investigation of nocturnal polyuria). Comparison of pre- and post-TTNS IPSS measures shown in Table 1.

Conclusions: TTNS is an inexpensive, low-risk, non-surgical treatment for $\mathrm{OAB}$ that can dramatically improve patient outcomes. Although this is a small study, it has shown promising results that can be analyzed in future studies with larger numbers.

\section{UP-119}

Improving patient outcomes in overactive bladder (OAB) with transcutaneous tibial nerve stimulation (TTNS): A systematic review

Christopher Ciampa', Anthony J. Kiosoglous

${ }^{1}$ Urology, Queen Elizabeth II Jubilee Hospital, Brisbane, Australia

Introduction: Transcutaneous tibial nerve stimulation (TTNS) is a nonsurgical treatment for overactive bladder (OAB) symptoms. It indirectly provides neuromodulation to the sacral plexus via the tibial nerve to alter voiding and storage functions of the bladder. There is no standardized protocol for TTNS therapy. This research systematically evaluated the effectiveness of different TTNS protocols for treating adults with idiopathic OAB (iOAB).

Methods: We conducted a systematic search of six databases for papers studying TTNS for $\mathrm{BOAB}$ in adults in past five years. Fifty-seven papers assessed for eligibility; three papers were found via reference harvesting and four grey literature records identified. Seven relevant studies were included for review (six randomized control trials, one prospective cohort study) (Fig. 1, Table 1).

Results: TTNS is effective, safe, and well-tolerated. Studies report significant reduction in OAB symptoms in $32-93 \%$ of patients, urge-incontinence cure rates of $25-45 \%$, and quality of life improvements of $43-72 \%$. Patients with iOAB who failed first-line therapy benefit from TTNS, and two trials reported statistical improvement in all clinical parameters after TTNS (regardless of sex/presence of neurological disorders). However, there is scant evidence to support long-term effectiveness. Clear limitation in TTNS research is an absence of standardized treatment protocol (frequency/duration) and outcome measure tools (OMTs) used. Most studies use a combination of two OMTs (i.e., pre/post-treatment bladder diary measures with a standardized OAB questionnaire (i.e., ICIQ-OAB) but this is inconsistent, which creates difficulty in assessing TTNS effectiveness (Tables 2, 3).

Conclusions: All studies show benefit from TTNS. It is safe, tolerable, minimally invasive, and inexpensive. Further studies are needed to identify optimal treatment regimen/OMTs used to define ideal therapy administration, long-term success, and financial benefit to enable accurate documentation of TTNS efficacy. 


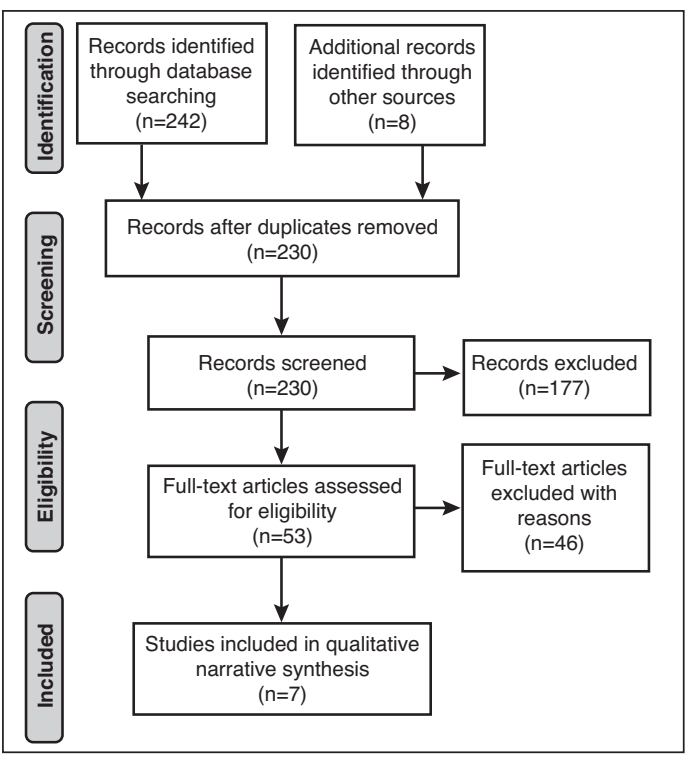

UP-119. Fig. 1. PRISMA flowchart of above search and selection method. Adapted from: Moher D, et al. Preferred Reporting Items for Systematic Reviews and Meta-Analyses: The PRISMA statement. PLoS Med 2009;6:e1000097.

\begin{abstract}
UP-120
Adjustable trans-obturator male system (ATOMS) for stress urinary incontinence: New Zealand experience

Mohit Bajaj', Jeremy Wild', Giovanni LosCo², Andre Westenberg ${ }^{1}$

1 Urology, Tauranga Hospital, Bay of Plenty District Health Board,

Tauranga, New Zealand; '2Urology, Christchurch Hospital, Canterbury District Health Board, Christchurch, New Zealand

Introduction: The adjustable trans-obturator male system (ATOMS) is a novel continence device in the management of mild to moderate stress urinary incontinence (SUI). While long-term efficacy and safety studies have been conducted in multicenter European trials, clinical experience in Australasia is limited. We present the results of a New Zealand operative series with the ATOMS, incorporating the experience of two surgeons, focusing on efficacy and safety outcomes. To our knowledge, this is the largest ATOMS series published since the landmark multicenter European studies.

Methods: A retrospective review of all ATOMS devices placed between May 2015 and August 2020 was conducted. Urodynamic assessments to assess leak point pressures were performed preoperatively for all patients. Severity of incontinence was assessed (pad usage) before and after surgery. Overall success rate (improvement in daily pad use), dry rate $(0-1$ $\mathrm{pad} /$ day), device durability, treatment failure, and device complications were recorded.

Results: A total of 130 patients were reviewed, with the most common indication for ATOMS placement being SUI post-radical prostatectomy $(85 \%) ; 37 \%$ of patients $(n=48)$ had previous radiotherapy for malignancy, while previous continence surgeries had been performed in $19 \%(n=25)$. All men had low leak point pressures $(<100 \mathrm{~cm})$ on urodynamic assess-
\end{abstract}

\begin{tabular}{|c|c|c|c|c|c|c|c|c|c|}
\hline Study & $\begin{array}{l}\text { Patients } \\
\text { (n) }\end{array}$ & $\begin{array}{l}\text { Gender } \\
\text { (F) }\end{array}$ & $\begin{array}{l}\text { Gender } \\
\text { (M) }\end{array}$ & $\begin{array}{l}\text { Treated } \\
\text { (n) }\end{array}$ & Control (n) & $\begin{array}{l}\text { Protocol } \\
\text { (duration) }\end{array}$ & $\begin{array}{c}\text { Protocol } \\
\text { (frequency) }\end{array}$ & $\begin{array}{l}\text { Outcome } \\
\text { measure }\end{array}$ & Conclusion \\
\hline $\begin{array}{l}\text { Teixeira } \\
\text { (RCT), } 2020\end{array}$ & 101 & 101 & 0 & 72 & 29 (sham) & $\begin{array}{c}8 \text { sessions } \\
4 \text { weeks }\end{array}$ & $\begin{array}{l}30 \text { mins } \\
2 x / \text { week }\end{array}$ & $\begin{array}{c}\mathrm{BD}+ \\
\mathrm{ICIQ}-\mathrm{OAB}\end{array}$ & $\begin{array}{c}\text { Effective in older patients, } \\
\text { no difference in treatment } \\
\text { thresholds }\end{array}$ \\
\hline $\begin{array}{l}\text { Welk (RCT), } \\
2020\end{array}$ & 50 & 50 & 0 & 26 & 24 (sham) & $\begin{array}{l}36 \text { sessions } \\
12 \text { weeks }\end{array}$ & $\begin{array}{l}30 \mathrm{mins} \\
3 \mathrm{x} / \text { week }\end{array}$ & $\begin{array}{l}\mathrm{BD}+ \\
\mathrm{OAB}-\mathrm{q}\end{array}$ & $\begin{array}{l}\text { TTNS does not appear effective } \\
\text { in improving symptoms of OAB }\end{array}$ \\
\hline $\begin{array}{l}\text { Manriquez } \\
(\mathrm{RCT}), 2016\end{array}$ & 70 & 70 & 0 & 36 & 34 (ERO) & $\begin{array}{l}24 \text { sessions } \\
12 \text { weeks }\end{array}$ & $\begin{array}{l}30 \text { mins } \\
2 x / \text { week }\end{array}$ & $\begin{array}{l}\text { BD + } \\
\text { OAB-q }\end{array}$ & $\begin{array}{l}\text { TTNS is as effective as } \\
\text { extended-release oxybutynin as } \\
\text { a treatment option for } O A B\end{array}$ \\
\hline $\begin{array}{l}\text { Martin- } \\
\text { Garcia } \\
\text { (RCT), } 2019\end{array}$ & 24 & 24 & 0 & 12 & 12 (PTNS) & $\begin{array}{c}72 \text { sessions } \\
24 \text { weeks }\end{array}$ & $\begin{array}{l}30 \text { mins } \\
3 x / \text { week }\end{array}$ & $\begin{array}{l}\text { BD + } \\
\text { OAB-q }\end{array}$ & $\begin{array}{l}\text { TTNS is effective in the } \\
\text { maintenance of symptom } \\
\text { improvement in women } \\
\text { with OAB who had positively } \\
\text { responded to a course of } 12 \\
\text { weekly PTNS sessions }\end{array}$ \\
\hline $\begin{array}{l}\text { Ramirez- } \\
\text { Garcia } \\
\text { (RCT), } 2018\end{array}$ & 68 & 46 & 22 & 34 & 34 (PTNS) & $\begin{array}{c}12 \text { sessions } \\
12 \text { weeks }\end{array}$ & $\begin{array}{l}30 \text { mins } \\
1 \mathrm{x} / \text { week }\end{array}$ & $\begin{array}{l}\mathrm{BD}+ \\
\mathrm{I}-\mathrm{QOL}\end{array}$ & $\begin{array}{c}\text { TTNS overall effective }+ \text { non- } \\
\text { inferior when compared with } \\
\text { PTNS }\end{array}$ \\
\hline $\begin{array}{l}\text { Valles } \\
\text { (PCS), } 2017\end{array}$ & 65 & 41 & 24 & 65 & 0 & $\begin{array}{l}10 \text { sessions } \\
10 \text { weeks }\end{array}$ & $\begin{array}{l}30 \text { mins } \\
1 x / \text { week }\end{array}$ & $\begin{array}{l}\mathrm{BD}+ \\
\mathrm{OAB}-\mathrm{q} \\
\text { single } \\
\text { question }\end{array}$ & $\begin{array}{l}\text { TTNS is an effective and } \\
\text { well tolerated treatment in } \\
\text { patients with urge incontinence } \\
\text { refractory to first- and second- } \\
\text { line therapies }\end{array}$ \\
\hline Total & 363 & 341 & 22 & 205 & 158 & $\begin{array}{l}\text { Mean: } \\
\text { sessions: } \\
24.29 \\
\text { Weeks: } \\
11.14\end{array}$ & $\begin{array}{c}\text { Mean: } \\
2.17 x / \text { week }\end{array}$ & & \\
\hline
\end{tabular}




\begin{tabular}{|c|c|c|c|c|c|c|}
\hline Study & $\begin{array}{l}\text { Pre-treatment } \\
\text { (recorded } \\
\text { episodes) }\end{array}$ & $\begin{array}{l}\text { Post-treatment } \\
\text { (recorded } \\
\text { episodes) }\end{array}$ & $\begin{array}{c}\text { Percentage } \\
\text { change }\end{array}$ & $\begin{array}{l}\text { Pre-comparator } \\
\text { (recorded } \\
\text { episodes) }\end{array}$ & $\begin{array}{l}\text { Post- } \\
\text { comparator } \\
\text { (recorded } \\
\text { episodes) }\end{array}$ & $\begin{array}{l}\text { Percentage } \\
\text { change }\end{array}$ \\
\hline $\begin{array}{l}\text { Valles et al, } 2017 \text { - PCS } \\
\text { (Reported mean difference } \\
\text { of BD + OABq, pre- and } \\
\text { post-treatment) } \\
\text { [No comparator] }\end{array}$ & $\begin{array}{l}\text { DFx: } 8.24 \\
\text { NFx: } 2.5 \\
\text { Urgency: } 2.25 \\
\text { Pads: } 1.78\end{array}$ & $\begin{array}{l}\text { DFx: } 7.48 \\
\text { NFx: } 1.03 \\
\text { Urgency: } 1.34 \\
\text { Pads: } 1.0\end{array}$ & $\begin{array}{l}\text { DFx: } 9.22 \% \\
\text { NFx: } 58.8 \% \\
\text { Urgency: } 40.44 \% \\
\text { Pads: } 43.82 \%\end{array}$ & & & \\
\hline $\begin{array}{l}\text { Teixeira et al, } 2020- \\
\text { RCT (compared TTNS } \\
\text { (at different amplitude } \\
\text { thresholds with sham) } \\
\text { [Comparator=sham] }\end{array}$ & $\begin{array}{l}\text { DFx: } 11.81 / 11.50 \\
\text { NFx: } 2.13 / 2.70 \\
\text { Urgency: } \\
2.21 / 2.55 \\
\text { UUI: } 1.49 / 2.05\end{array}$ & $\begin{array}{l}\text { DFx: } 7.84 / 7.88 \\
\text { NFx: } 1.05 / 1.36 \\
\text { Urgency: } \\
0.51 / 0.84 \\
\text { UUI: } 0.26 / 1.82\end{array}$ & $\begin{array}{l}\text { DFx: } 32.54 \% \\
\text { NFx: } 50.16 \% \\
\text { Urgency: } 71.99 \% \\
\text { UUI: } 72.49 \%\end{array}$ & $\begin{array}{l}\text { DFx: } 12.4 \\
\text { NFx: } 2.49 \\
\text { Urgency: } 2.14 \\
\text { UUI: } 1.82\end{array}$ & $\begin{array}{l}\text { DFx: } 11.79 \\
\text { NFx: } 2.45 \\
\text { Urgency: } 2.21 \\
\text { UUI: } 1.82\end{array}$ & $\begin{array}{c}\text { DFx: } 4.92 \% \\
\text { NFx: } 1.61 \% \\
\text { Urgency: } 2.21 \% \\
\text { UUI: } 1.82 \%\end{array}$ \\
\hline $\begin{array}{l}\text { Jacomo et al, } 2020-\text { RCT } \\
\text { (compared TTNS to PSS) } \\
\text { [Comparator=PSS] }\end{array}$ & $\begin{array}{l}\text { DFx: } 7.3 \\
\text { NFx: } 1.8 \\
\text { Urgency: } 1.33 \\
\text { UUI: } 1.49\end{array}$ & $\begin{array}{l}\text { DFx: } 6.66 \\
\text { NFx: } 1.6 \\
\text { Urgency: } 1.33 \\
\text { UUI: } 0.33\end{array}$ & $\begin{array}{c}\text { DFx: } 9 \% \\
\text { NFx: } 12.57 \% \\
\text { Urgency: } 0 \% \\
\text { UUl: } 77.85 \%\end{array}$ & $\begin{array}{l}\text { DFx: } 6.96 \\
\text { NFx: } 1.66 \\
\text { Urgency: } 1.16 \\
\text { UUI: } 1.66\end{array}$ & $\begin{array}{l}\text { DFx: } 6.0 \\
\text { NFx: } 1.0 \\
\text { Urgency: } 0.33 \\
\text { UUI: } 1.16\end{array}$ & $\begin{array}{l}\text { DFx: } 13.79 \% \\
\text { NFx: } 39.76 \% \\
\text { Urgency: } 71.55 \% \\
\text { UUI: } 30.12 \%\end{array}$ \\
\hline $\begin{array}{l}\text { Manriquez et al, } 2016-\mathrm{RCT} \\
\text { (compared TTNS to ERO) } \\
\text { [Comparator=ERO] }\end{array}$ & $\begin{array}{l}\text { DFx: } 24 \\
\text { Urgency: } 14 \\
\text { UUl: } 5.5 \\
\text { Pads: } 7.5\end{array}$ & $\begin{array}{l}\text { DFx: } 18 \\
\text { Urgency: } 5 \\
\text { UUI: } 0 \\
\text { Pads: } 2\end{array}$ & $\begin{array}{c}\text { DFx: } 25 \% \\
\text { Urgency: } 64.29 \% \\
\text { UUI: } 100 \% \\
\text { Pads: } 73.33 \%\end{array}$ & $\begin{array}{l}\text { DFx: } 28 \\
\text { Urgency: } 16 \\
\text { UUl: } 3.5 \\
\text { Pads: } 8.5\end{array}$ & $\begin{array}{l}\text { DFx: } 20.5 \\
\text { Urgency: } 4.5 \\
\text { UUI: } 0 \\
\text { Pads: } 0\end{array}$ & $\begin{array}{l}\text { DFx: } 26.79 \% \\
\text { Urgency: } \\
71.87 \% \\
\text { UUI: } 100 \% \\
\text { Pads: } 100 \%\end{array}$ \\
\hline $\begin{array}{l}\text { Martin-Garcia et al, } 2019 \\
\text { - RCT } \\
\text { (compared TTNS and PTNS) } \\
\text { symptoms measured } \\
\text { at baseline/6 weeks/3 } \\
\text { months/6 months } \\
\text { [Comparator=PTNS] }\end{array}$ & $\begin{array}{l}\text { DFx: } 8.5 \\
\text { Urgency: } 1.7 \\
\text { UUI: } 0.5\end{array}$ & $\begin{array}{c}\text { DFx: } 7.7 / 7.5 / 7.7 \\
\text { Urgency: } \\
3.2 / 2.5 / 2.0 \\
\text { UUI: } 0.5 / 0.2 / 0.2\end{array}$ & $\begin{array}{l}\text { DFx: } 9.4 \% \\
\text { Urgency: } 0 \% \\
\text { UUI: } 60 \%\end{array}$ & $\begin{array}{l}\text { DFx: } 7.3 \\
\text { Urgency: } 2.0 \\
\text { UUI: } 0\end{array}$ & $\begin{array}{c}\text { DFx: } 8.3 / 8.5 / 8.7 \\
\text { Urgency: } \\
0.7 / 1.3 / 0.5 \\
\text { UUI: } 0 / 0.5 / 0\end{array}$ & $\begin{array}{l}\text { DFx: } 0 \% \\
\text { Urgency: } 75 \% \\
\text { UUI: } 0 \%\end{array}$ \\
\hline
\end{tabular}

ment. Men were followed up for a median period of 16 months. Overall success rate was $81 \%$, with a dry rate of $75 \%$. Recorded postoperative complications included urinary retention $(1.5 \%, \mathrm{n}=2)$, transient perineal numbness $(20 \%, \mathrm{n}=26)$, infection $(4.6 \%, \mathrm{n}=6)$, and device explantation due to persisting leakage requiring further surgery $(16 \%, n=21)$.

Conclusions: Treatment of mild to moderate male SUI with the ATOMS is safe and effective. The option of long-term, minimally invasive adjustment to respond to patient needs is a significant advantage.

\section{UP-121}

Impact of radiotherapy for prostate cancer on bladder function as demonstrated on urodynamics study: A systematic review

Venetia Hoe ${ }^{1}$, Henry Yao 1,2,3,4, Samer Shamout ${ }^{3,4}$, Shomik Sengupta ${ }^{2}$, Helen O'Connell', Kevin V. Carlson ${ }^{3,4}$, Richard J. Baverstock ${ }^{3,4}$

${ }^{1}$ Urology, Western Health, Melbourne, Australia; ${ }^{2}$ Eastern Health Clinical School, Eastern Health, Melbourne, Australia; ${ }^{3}$ vesia [Alberta Bladder Centre], Calgary, $\mathrm{AB}$, Canada; ${ }^{4}$ Surgery, University of Calgary, Calgary, AB, Canada

Introduction: Lower urinary tract symptoms (LUTS) are a well-known side effect of radiotherapy (RT) treatment for prostate cancer, due to genitourinary toxicity. There is a paucity of data on bladder function following
RT for prostate cancer. This study aims to describe the effects of bladder function following RT treatment of prostate cancer by performing a systematic review on urodynamic findings before and after RT.

Methods: This systematic review was conducted in accordance with the PRISMA guideline. A systematic search was conducted using PubMed, Cochrane library, Scopus, and OVID Embase. Studies were included if they involved men who underwent urodynamic studies following RT treatment for localized prostate cancer. A total of 798 articles were screened to assess for eligibility, with five articles included in the final review. A qualitative analysis was performed.

Results: Patient reported outcome measures on LUTS following RT was poorly reported in conjunction with urodynamic studies. Bladder compliance was found to worsen following RT, especially over time, with decreased compliance reported in $18.8 \%$ and $62.5 \%$ of patients at three and 92.4 months, respectively. Bladder capacity was also found to worsen, with studies reporting reductions in maximum cystometric capacity from $-53 \mathrm{ml}$ to $-94 \mathrm{ml}$ at 3-22 months post-RT. Compared to baseline, bladder outlet obstruction (BOO) was largely persistent at three and 18 months following RT, while detrusor overactivity (DO) appeared to remain largely the same and slightly worse at 18 months.

Conclusions: Urodynamic studies show that RT impairs bladder capacity and compliance. Compared to radical prostatectomy (RP), resolution of 
BOO and DO appear to be less significant following RT, likely because RT does not resolve $\mathrm{BOO}$ to the same extent as RP, and a significant portion of patients' DO at baseline is concurrent to $\mathrm{BOO}$ secondary to benign prostatic hyperplasia. Further high-quality, larger, prospective studies are important to elucidate these outcomes.

\section{UP-122}

Urodynamics finding of detrusor overactivity underestimates the prevalence of overactive bladder in men following radical prostatectomy

Henry Han-I Yao ${ }^{1,2,3}$, Robert Trafford Crump ${ }^{2}$, Jing Jiang ${ }^{2}$, Carly Barton ${ }^{1,2}$, Catalina Vasquez ${ }^{4}$, John Lewis ${ }^{4}$, Kevin V. Carlson ${ }^{1,2}$, Richard J. Baverstock ${ }^{1,2}$ ${ }^{1}$ vesia [Alberta Bladder Centre], Southern Alberta Institute of Urology, Calgary, $A B, C$ Canada; ${ }^{2}$ Department of Surgery, University of Calgary, Calgary, AB, Canada; ${ }^{3}$ Eastern Health Clinical School, Monash University, Melbourne, Australia; ${ }^{4}$ Department of Oncology, University of Alberta, Edmonton, AB, Canada

Support: Dave Bateman. Prostate Cancer Centre, Southern Alberta Institute of Urology, Calgary, Alberta, Canada. Prostate Cancer Canada. Movember Foundation.

Introduction: This study aimed to determine the rates of overactive bladder $(\mathrm{OAB})$ in men with localized prostate cancer following treatment with radical prostatectomy (RP) as determined by OAB-V8 symptom score and urodynamics study.

Methods: This is a prospective pre-post case series of Canadian men with newly diagnosed localized prostate cancer treated with RP. Thirty-one men were recruited from June 2017 to July 2018. Clinicopathological data were extracted from medical records and Alberta Prostate Cancer Research Initiative database. Patient-reported outcome measures (PROMs), including Overactive Bladder-Validated 8-question Screener (OAB-V8) and Expanded Prostate Cancer Index Composite (EPIC)-26 short-form, were collected at baseline and 12 months. OAB was defined as OAB-V8 score $\geq 8$. Urodynamics study was offered only to men with OAB. Paired t-tests were used to compare PROMs score pre- and post-RP. Incontinence rate based on EPIC-26 was compared for men with and without OAB. Ethics approval was obtained for this study.

Results: At baseline, $54.8 \%$ of men had OAB, which increased to $64.5 \%$ at 12 months. There was no difference between baseline and 12 months OAB-V8 score on paired t-test; $41.9 \%$ of men had persistent OAB, $12.9 \%$ had resolution of $O A B$, and $22.6 \%$ developed de novo OAB after RP. Men without OAB had a higher continence rate post-RP based on EPIC-26 question $1(90.0 \%$ vs. $40 \%, \mathrm{p}=0.008)$. Detrusor overactivity (DO) was found in $40 \%$ of men who underwent urodynamics at baseline and $38.5 \%$ post-RP.

Conclusions: $O A B$ is present in approximately half of men with localized prostate cancer and can persist in the first 12 months following RP. This study suggests that men with OAB may have worse incontinence post-RP. This small series suggest that only approximately $40 \%$ of men with $O A B$, based on an OAB-V8, have demonstrable DO on urodynamics. Therefore, treatment of $\mathrm{OAB}$ as a component of incontinence management post-RP should be optimized based on symptoms even in the absence of DO on urodynamics. Further prospective and larger studies are required to confirm the findings of this study.

\begin{tabular}{|c|c|c|c|c|}
\hline \multicolumn{5}{|c|}{$\begin{array}{l}\text { UP-123. Table 1. Improvement in mean voiding } \\
\text { parameters from baseline to last followup }\end{array}$} \\
\hline & $\begin{array}{c}\text { Mean } \\
\text { baseline } \\
\text { (SD) }\end{array}$ & $\begin{array}{l}\text { Mean last } \\
\text { FU (SD) }\end{array}$ & $\begin{array}{c}\text { Mean } \\
\text { absolute } \\
\text { difference }\end{array}$ & $\begin{array}{c}\text { Mean } \\
\text { difference } \\
\text { percentage }\end{array}$ \\
\hline PVR (mL) & $\begin{array}{c}351.60 \\
(163.96)\end{array}$ & $\begin{array}{c}137.50 \\
(113.04)\end{array}$ & -214.10 & $-61 \%$ \\
\hline $\begin{array}{l}\text { CIC } \\
\text { (episodes/24h) }\end{array}$ & $4.36(1.65)$ & $1.19(1.55)$ & -3.17 & $-73 \%$ \\
\hline
\end{tabular}

\section{UP-123}

Retrospective study of the long-term efficacy of sacral nerve stimulation in underactive bladder patients: A single institution experience

Cristina Alina Evoescu ${ }^{1}$, Salima Ismail', Béatrice Bouchard ${ }^{1}$, Le Mai Tu ${ }^{1}$ ${ }^{1}$ Surgery Department/Division of Urology, University of Sherbrooke, Sherbrooke, QC, Canada

Introduction: Currently, sacral nerve stimulation (SNS) remains the only surgical treatment approved by the U.S. Food and Drug Administration for cases of underactive bladder (UAB) without bladder outlet obstruction. It has been showed to be effective in reducing the need for clean intermittent catherization $(\mathrm{CIC})$ and post-void residual volume (PVR). Nevertheless, UAB and SNS have only recently sparked interest in the research community. The objective of this research was to assess the long-term functional outcomes of SNS for UAB treatment.

Methods: All consecutive patients suffering from $U A B$ and treated by SNS at the Centre Hospitalier Universitaire de Sherbrooke between July 2007 and August 2019 were included. Data regarding patient demographics, SNS parameters, revision rates, complications, and outcomes of stimulation were collected.

Results: Twenty-four patients with a median age of 56.5 years (interquartile range [IQR] 53-61) were included. All procedures had been done under local anesthesia with light intravenous sedation. Median followup time was of 52.5 months (IRQ 20.3-116.3). Fifteen patients (62.5\%) had bilateral and nine patients $(37.5 \%)$ had unilateral SNS. PVR and number of $\mathrm{CIC}$ decreased by $61 \%$ and $73 \%$, respectively, from baseline to last followup (Table 1). CIC has been completely stopped in 11 patients $(45.8 \%)$. Revision surgeries were performed in 11 patients for broken electrode $(n=6,25.0 \%)$ and displaced electrode $(n=2,8.3 \%)$. SNS devices were permanently removed in two $(12.5 \%)$ patients due to important unpleasant motor contractions and lack of efficacy. There was infection $(2.4 \%)$ secondary to the chronic cutaneous Staphylococcus aureus infection. The device was repositioned in an antibiotic coated pouch and repositioned in a different site without further complication.

Conclusions: Patients with $U A B$ showed an important reduction of PVR and number of $\mathrm{CIC}$ with SNS. Moreover, it is a well-tolerated minimally invasive therapy that requires few revision surgeries. This supports the role of SNS in the treatment of $U A B$ in a subgroup of patients.

\section{UP-124}

Antagonism of the p75NTR receptor decreases MMP-9 activity and increases nerve growth factor (NGF) in urothelial cells

Aalya Hamouda ${ }^{7}$, Philippe Cammisotto ${ }^{1}$, Lysanne Campeau

'Lady Davis Institute for Medical Research, McGill University, Montreal, QC, Canada

Introduction: Decreased levels of nerve growth factor (NGF) have been observed in the urine of patients with overactive bladder syndrome (OAB) and of diabetic animal models. This unbalance appeared to result from an increased activity of the proteolytic enzyme metalloproteinase-9 (MMP-9). On the other hand, THX-B, an inhibitor of p $75^{\mathrm{NTR}}$, restored normal levels of NGF in mice with type 1 diabetes. Herein, we examined in vitro the effect of THX-B on the activity of MMP-9 in bladder cells.

Methods: Primary culture of urothelial and smooth muscle cells (SMCs) were grown from mouse bladder and exposed to p75NTR antagonist THX. The expression of NGF and MMP-9 were assessed by RT-qPCR, by immunohistochemistry and by immunoblotting. Levels of microRNAs were measured by RT-qPCR. NGF and proNGF secretion were measured by ELISA kits and MMP-9 activity by enzymatic assays.

Results: The mRNAs for NGF and MMP-9 were detected and found expressed in both cell types at similar level. Microscopy confirmed the localization of both proteins in cells. Urothelial cells and SMCs were both major source of NGF and proNGF. On the other hand, MMP-9 protein content was seven times higher in SMCs than in urothelial cells, which was confirmed by high levels of miR-491-5p in the latter. However, secretion of active MMP-9 in the medium was 40 times higher in urothelial 
cells medium. Incubation with THX-B $(5 \mu \mathrm{g} / \mathrm{mL})$ for 24 hours abolished the synthesis and secretion of MMP-9 and doubled the concentration of NGF in the medium of urothelial cells. ProNGF secretion levels were not affected. THX-B had little effects on SMCs both at the level of NGF and MMP-9.

Conclusions: Urothelial cells appear to be the primary target for THX-B to modulate secretion of NGF and MMP-9. These results are in accordance with our previous publications on $\mathrm{OAB}$ patients and diabetes type 1 in rodents and suggest that THX-B could be a therapeutic tool to improve $\mathrm{OAB}$ by targeting primarily the urothelium.

\section{UP-125}

A cost-effectiveness analysis of bladder management strategies in neurogenic lower urinary tract dysfunction after spinal cord injury: A publicly funded healthcare perspective

Samer Shamout ${ }^{1,3}$, Sara Nazha ${ }^{1,2}$, Alice Dragomir ${ }^{1,2}$, Lysanne Campeau $^{1}$ 'Department of Surgery, Division of Urology, McGill University, Montreal, QC, Canada; ${ }^{2}$ Faculty of Medicine, McGill University, Montreal, QC, Canada; ${ }^{3}$ Department of Surgery, Division of Urology, University of Calgary, Calgary, AB, Canada

Introduction: Intermittent catheterization remains the gold standard management strategy for neurogenic lower urinary tract dysfunction (NLUTD) related to spinal cord injury $(\mathrm{SCl})$. This study aims to investigate the longterm cost-effectiveness of clean intermittent catheterization $(\mathrm{CIC})$ com- pared with suprapubic catheters (SPC) and indwelling urethral catheters (UC) among individuals with neurogenic lower urinary tract dysfunction due to spinal cord injury from a Canadian healthcare perspective.

Methods: A Markov model with Monte Carlo simulation was developed with a cycle length of one year and lifetime horizon to estimate the incremental cost per quality-adjusted life years (QALYs). Patients were assigned to treatment with either CIC or SPC or UC. Transition probabilities, efficacy data, and utility values were derived from published literature and expert opinion. Costs were obtained from provincial healthcare system and hospital data in Canadian dollars. The primary outcome was cost per QALY. A standard discount rate of $1.5 \%$ was applied annually. Probabilistic and one-way deterministic sensitivity analyses were performed to evaluate the robustness of the model.

Results: CIC had a lifetime mean total cost of \$ 29161 for 20.91 QALYs, while UC had a mean total cost of \$31 657 for 18.95 QALYs and SPC had a mean cost of \$ 29491 for 19.14 QALYs. The model predicted that a 40-year-old patient with $\mathrm{SCl}$ would gain an additional 1.72 QALYs if $\mathrm{CIC}$ were used instead of SPC, at an incremental cost savings of $\$ 330$. $\mathrm{CIC}$ confer $1.96 \mathrm{QALYs}$ and three discounted life-years gained compared to UC, with an incremental cost savings of $\$ 2496$.

Conclusions: Intermittent catheterization appears to be a dominant and more economically attractive bladder management strategy for NLUTD compared with SPC and/or UC from the public payer perspective over a lifetime horizon. 